\section{EURODEP Consortium and late-life depression ${ }^{\dagger}$}

DAN BLAZER prevalence of depression among younger persons?" This question came to prominence with the reports from the ECA studies, in which the counterintuitive finding emerged, site after site, that late-life depression was not as frequent as previously believed and was no more frequent in the elderly than at earlier ages (Weissman $e t$ al, 1988). As noted by the authors, these findings depend upon case definition and methods of case ascertainment, constraints which Professor Copeland has been discussing for years. The EURODEP findings confirm yet again that the burden of depression among the elderly is high (no one seriously ever suggested otherwise) yet the frequency of major depression (the most severe of the depressive syndromes), as operationalised in DSM-III (American Psychiatric Association, 1980), its successors and analogous operationalised criteria throughout the world, is no higher among communitydwelling elders than among the young and the middle-aged. What these findings do not account for is the role of comorbidity (dementing disorders and physical illness) which is common among the elderly, yet not considered in the operationalised criteria for major depression. In retrospect, the question: "What is the true prevalence of depression in late life?" cannot be answered, for whatever estimate of depression emerges from a study will reflect the methods of the study as much as the suffering of the subjects. For this reason, the question is not that interesting.

\section{THE QUESTION OF GEOGRAPHICAL DIFFERENCES}

Yet the EURODEP study does highlight a most interesting question: "Why does the frequency of late-life depression vary from one country to another?" The investigators report a two-fold difference among elders across the sites of these epidemiological studies which I do not believe can be explained by the methods of the study alone. We live in an era during which the study of the biology of psychiatric disorders is in the ascendance. Vascular lesions of the subcortex, dysregulation of chemical messengers or circadian rhythms and genotype are the risk factors most often explored. Of course, biological factors could explain geographical differences, such as a difference in genotype. Yet this is not the most parsimonious explanation, nor the explanation which 
best fits these data. For example, among the more significant differences were those between London and Liverpool. Psychosocial risk factors, on the other hand, are acknowledged by psychiatrists but do not appear to excite most of us at the end of the 20th century. Social psychiatry has almost disappeared as a discipline in the USA. Nevertheless, the biopsychosocial model, which has served us so well for so many years, still applies. The EURODEP investigators have the ability to explore in much greater depth these geographical differences. If they are as clever in devising methods for comparing psychosocial risk factors as they have been in developing the EURO-D, some most interesting findings could emerge. These findings will not only inform more biologically inclined psychiatrists, who must accommodate these factors in their models (and many do), also they will inform clinicians who care for older people experiencing

DAN G. BLAZER, PhD. Duke University Medical Center, School of Medicine, Durham, NC 27710, USA Fax: 9196817640

(First received 24 November 1998, accepted 4 December 1998)

depression in the context of a social environment that is a very real factor in the onset, character and duration of late-life depression.

\section{REFERENCES}

American Poychiatric Association (1980) Diognostic and Statistical Manual of Mental Disorders (3rd edn) (DSM- III). Washington, DC: APA

Beekman, A.T. F., Copeland, J. R. M. \& Prince, M. J. (1999) Review of community prevalence of depression in later life. British Journal of Psychiatry, 174, 307-311.

Blazer, D. G. (1997) Depression in the elderly. Myths and misconceptions. Psychiatric Clinics of North America, 20, III-119.
Regier, D. A., Boyd, J. M., Burke, J. D., Jr., et al (1988) One-month prevalence of mental disorders in the United States. Based on five Epidemiologic Catchment Area sites. Archives of General Psychictry. 45, 977.986

Robins, L. N., Helzer, J. E., Croughan, J., et ol (1981) National Institute of Mental Health diagnostic interview schedule: its history, characteristics and validity. Archives of General Psychiatry, 38 $381-389$.

Weissman, M. M., Leaf, P. J., Tischler, G. L., et ol (1988) Affective disorders in five United States communities. Psychological Medicine, 18. $14 \mid-153$

_, Bland, R. \& Canino, G. (1996) Cross-national epidemiology of major depression and bipolar disorder Journal of the American Medical Association, 276. 293-299. 